\title{
Influence of Cadmium(II) Ions and Brewery Sludge on Metallothionein Level in Earthworms (Eisenia fetida) - Bio- transforming of Toxic Wastes
}

\author{
Dalibor Huska $^{1,2}$, Sona Krizkova ${ }^{1}$, Miroslava Beklova ${ }^{3}$, Ladislav Havel ${ }^{2}$, Josef Zehnalek ${ }^{1}$, \\ Vaclav Diopan ${ }^{1,2}$, Vojtech Adam ${ }^{1,4}$, Ladislav Zeman ${ }^{4}$, Petr Babula ${ }^{5}$ and Rene Kizek ${ }^{1, *}$ \\ 1 Department of Chemistry and Biochemistry, 2 Department of Plant Biology, and 4Department of \\ Animal Nutrition and Forage Production, Faculty of Agronomy, Mendel University of Agriculture and \\ Forestry, Zemedelska 1, CZ-613 00 Brno, Czech Republic \\ 3 Department of Veterinary Ecology and Environmental Protection, Faculty of Veterinary Hygiene \\ and Ecology, and 5 Department of Natural Drugs, Faculty of Pharmacy and University of Veterinary \\ and Pharmaceutical Sciences, Palackeho 1-3, CZ-612 42 Brno, Czech Republic
}

* Author to whom correspondence should be addressed; E-mail:kizek@sci.muni.cz

Received: 31 January 2008 / Accepted: 14 February 2008 / Published: 19 February 2008

\begin{abstract}
Metallothioneins belong to a group of intracellular, high molecular and cysteine-rich proteins whose content in an organism increase with increasing concentration of a heavy metal. The aim of this work was to apply the electrochemical analysis for the analysis of metallothioneins in earthworms exposed to cadmium ions and brewery sludge. Here we utilized adsorptive transfer technique coupled with differential pulse voltammetry Brdicka reaction to determine metallothionein in different biological samples. By means this very sensitive technique it was possible to analyze metallothionein in concentrations below $1 \mu \mathrm{mol} .1^{-1}$ with the standard deviation of $4-5 \%$. We found out that the average MT level in the non-treated earthworms oscillated between 19 and $48 \mu \mathrm{mol}^{-1} \mathrm{l}^{-1}$. When we analysed samples of earthworms treated by cadmium, we observed that the MT content increased with the exposition length and increase dose of cadmium ions. Finally, we attempted to study and compare the toxicity of the raw sludge and its leach by using of earthworms. The raw brewery sludge caused the death of the earthworms quickly. Earthworms held in the presence of leach from brewery sludge increased their weight of $147 \%$ of their original weight because they ingested the nutrients from the sludge. The metallothionein level changes markedly with increasing time of exposition and applied
\end{abstract}


dose of toxic compound. It clearly follows from the obtained results that the MT synthesis is insufficient in the first hours of the exposition and increases after more than $24 \mathrm{~h}$.

Keywords: Metallothionein; Biochemical marker; Cadmium; Heavy metals; Earthworm; Electrochemistry; Voltammetry

\section{Introduction}

According to the principles of environment protection in the Czech Republic, the markedly increase of sewage-farm sludge's production from various sources can be expected. Their processing and disposing is one from the most important troubles connected with waste water purification. The sludge coming from plants of industrial purpose often contains dangerous compounds like heavy metals, organic residues and pathogenic organisms. During the waste water disposing the adsorption of heavy metals to activated and biological sludge occurs. From 20 to $90 \%$ of total content of heavy metals in the sludge can be removed by waste-water disposing according to its technological parameters, age of the sludge and its $\mathrm{pH}$ value. Cadmium and lead can be removed effectively from the waste water by procedures based on physically-chemical processes. High concentration of toxic heavy metals in sludge can influence negatively their utilizing for fertilization and composting. In addition, the utilizing of the sludge can be markedly improved by biological disposing through using of various microorganisms, fungi and animals [1-7].

The ecotoxicological markers such as various peptides and proteins could be very useful tool for rapid and easy assessment of the sludge toxicity [8,9]. Metallothioneins (MTs) is thought to be a marker of environment polluting by heavy metals [10]. MTs belongs to group of intracellular and cysteine-rich proteins with molecular weight from 6 to $10 \mathrm{kDa}$ [10-12], which are able to bind heavy metal ions thanks to its high cysteine content. MTs consist of two binding domains $(\alpha, \beta)$ that are assembled from cysteine clusters. The heavy metals detoxification and maintaining of their homeostasis in an organism can be considered as the main physiological function of MTs [13-19]. The aim of this work was to investigate the effect of cadmium ions and brewery sludge on MT levels in earthworms (Eisenia fetida).

\section{Material and Methods}

\subsection{Chemicals and pH measurements}

Rabbit liver MT (MW 7143 g. $\mathrm{mol}^{-1}$ ), containing $5.9 \% \mathrm{Cd}$ and $0.5 \% \mathrm{Zn}$, was purchased from Sigma Aldrich (St. Louis, USA). $\mathrm{Co}\left(\mathrm{NH}_{3}\right)_{6} \mathrm{Cl}_{3}$ and other chemicals used were purchased from Sigma Aldrich unless noted otherwise. The stock standard solutions of MT $\left(10 \mu \mathrm{g} \cdot \mathrm{ml}^{-1}\right)$ was prepared by ACS water (Sigma-Aldrich, USA) and stored in the dark at $-20{ }^{\circ} \mathrm{C}$. Working standard solutions were prepared daily by dilution of the stock solutions with ACS water. The $\mathrm{pH}$ value was measured using WTW inoLab Level 3 with terminal Level 3 (Weilheim, Germany), controlled by the personal computer program (MultiLab Pilot; Weilheim, Germany). The pH-electrode (SenTix-H, pH 0-14/3M $\mathrm{KCl}$ ) was regularly calibrated by set of WTW buffers (Weilheim, Germany). 


\subsection{Biological samples}

Earthworms (Eisenia fetida; average weight $0.25 \mathrm{~g}$ ) were kept at laboratory temperature in lid cultivation flasks which contained five litters of artificial soil (OECD 207) and $175 \mathrm{ml}$ of distilled water or $\mathrm{Cd}\left(\mathrm{NO}_{3}\right)_{2}$ solution. The earthworms were exposed to cadmium(II) ions $(0,5,10,20,30,40$ and $50 \mu \mathrm{mol} . \mathrm{l}^{-1}$ ) for seven days. The samples were collected daily. In the case of experiments with brewery sludge, flasks were filled with five litters of brewery sludge and/or its leach obtained from Cerna Hora Brewery (Cerna Hora, Czech Republic), whereas the earthworms were treated for fourteen days. After 14 days, earthworms were sampled and killed by deep-freezing. In the both experimental models, flasks were stored in digester with continuous lighting of 450 lux. The collected earthworms were weighed and subsequently grinded in the presence of $1 \mathrm{ml}$ of phosphate buffer $(50 \mathrm{mM}, \mathrm{pH} 7)$ by Ika A11 basic grinder (IKA Werke GmbH and Co., Staufen, KG, Germany).

\subsection{Preparation of biological samples for electrochemical analysis}

The grinded samples of earthworms (approximately $0.5 \mathrm{~g}$ ) were homogenized in liquid nitrogen, diluted with $1 \mathrm{ml}$ of phosphate buffer $(50 \mathrm{mM}, \mathrm{pH} 7)$, and vortexed for $15 \mathrm{~min}$ on Vortex-2 Genie (Scientific industries, USA). After that, the homogenised samples were heat treated and solvent precipitated (Petrlova et al, 2006). Briefly, the samples were kept at $99{ }^{\circ} \mathrm{C}$ in a thermomixer (Eppendorf 5430, USA) for 15 min with occasional stirring, and then cooled to $4 \mathrm{oC}$. The denatured homogenates were centrifuged at $4{ }^{\circ} \mathrm{C}, 15000 \mathrm{~g}$ for $30 \mathrm{~min}$. (Eppendorf 5402, USA). Heat treatment and solvent precipitation effectively denature and remove high molecular weight proteins out from samples.

\subsection{Electrochemical measurements}

Electrochemical measurements were performed with AUTOLAB Analyser (EcoChemie, Netherlands) connected to VA-Stand 663 (Metrohm, Switzerland), using a standard cell with three electrodes. The working electrode was a hanging mercury drop electrode (HMDE) with a drop area of $0.4 \mathrm{~mm}^{2}$. The reference electrode was an $\mathrm{Ag} / \mathrm{AgCl} / 3 \mathrm{M} \mathrm{KCl}$ electrode and the auxiliary electrode was a graphite electrode. For smoothing and baseline correction the software GPES 4.4 supplied by EcoChemie was employed. The Brdicka supporting electrolyte containing 1 mmol. $1^{-1} \mathrm{Co}\left(\mathrm{NH}_{3}\right)_{6} \mathrm{Cl}_{3}$ and $1 \mathrm{M}$ ammonia buffer $\left(\mathrm{NH}_{3}(\mathrm{aq})+\mathrm{NH}_{4} \mathrm{Cl}, \mathrm{pH}=9.6\right)$ was used and changed after five measurements; surface-active agent was not added. The samples of the MT were reduced before each measurement by $1 \mathrm{mM}$ tris(2-carboxyethyl)phosphine addition according to [20,21]. Adsorptive transfer stripping technique coupled with differential pulse voltammetry Brdicka reaction parameters were as follows: an initial potential of $-0.6 \mathrm{~V}$, an end potential $-1.6 \mathrm{~V}$, a modulation time $0.057 \mathrm{~s}$, a time interval $0.2 \mathrm{~s}$, a step potential of $1.05 \mathrm{mV} . \mathrm{s}^{-1}$, a modulation amplitude of $250 \mathrm{mV}$, temperature of supporting electrolyte of $5{ }^{\circ} \mathrm{C}, \mathrm{E}_{\mathrm{ads}}=0 \mathrm{~V}$. The temperature of supporting electrolyte was maintained by the flow electrochemical cell coupled with thermostat JULABO F12/ED (Labortechnik GmbH, Germany). Other details have been published by Petrlova et al. [21] and Adam et al. [22]. 


\subsection{Statistical analysis}

Data were processed using MICROSOFT EXCEL ${ }^{\circledR}$ (USA). Results are expressed as mean \pm S.D. unless noted otherwise. Statistical significance of the differences between MT in control and treated earthworms was determined. Differences with $\mathrm{p}<0.05$ were considered significant.

\section{Results and Discussion}

Heavy metals ions are very threaten for living organisms. For example, cadmium and lead are classified as very dangerous and toxic. These heavy metals are often cumulated in biosphere and can entry the human food chain $[23,24]$; moreover they are often present in various kinds of wastes.

\subsection{Changes in metallothionein level in earthworms exposed to cadmium ions}

Papers devoted to MT induction in earthworms under various stresses have been published [4,2527]. In addition the distribution of the MT isoforms has been studied by various specific techniques $[26,28,29]$. The given methods are appropriate for MT determination, but they are heavy for instrumentation. Electrochemical methods are also very appropriate for MTs determination, as shown in $[21,30]$. Thus we utilized adsorptive transfer technique coupled with differential pulse voltammetry Brdicka reaction to determine MT according to [21]. Use this very sensitive technique it was possible to analyze MT in concentrations below $1 \mu \mathrm{mol} .1^{-1}$ with the standard deviation of $4-5 \%$. The calibration curve measured in the presence of Brdicka supporting electrolyte at $5^{\circ} \mathrm{C}$ was linear $(y=4.87 \mathrm{x}+6.55$; $\mathrm{R}^{2}=0.9946$ ). Based on our previous experimental data the dilution of a homogenized sample of interest can markedly affect the electrochemical analysis. The earthworms' homogenates were diluted prior the analysis $(10 \times, 100 \times$ and $1000 \times)$. It was observed that the dilution of the sample of $1000 \times$ with phosphate buffer ( $\mathrm{pH}$ 7.0) was very advantageous for electrochemical analyses due to the lowest experimental deviations and the most reproducible results obtained. Thanks to this methodology, the voltammograms of the samples with very well defined catalytic signals of MT (Cat1, Cat2 and Cat3) were obtained. For our purposes the change of the signal Cat 3 was determined. We found out that the average MT level in the non-treated earthworms oscillated between 19 and $48 \mu \mathrm{mol}^{-1} \mathrm{l}^{-1}$ This variability could be associated with different metabolic activity of certain earthworms. The typical voltammograms of earthworms both exposed to cadmium ions and controls are shown in Figure 1. The curves obtained by analyzing control samples are very similar during the whole experiment, but the differences in voltammograms of earthworms exposed to seven different cadmium concentrations are well detectable [31]. The average MT level in samples of treated earthworms increased with the applied dose of cadmium(II) ions (see Table 1). The MT levels at the earthworms exposed to cadmium(II) ions varied from 17.9 to $99.9 \mu$ mol. $1^{-1}$. If these results have been subtracted from the control ones, the interesting experimental data were obtained. In the first day of the experiment the MT level determined in the exposed earthworms the same or even slightly lower in comparison with controls (Figure 2, column 1). This phenomenon can be associated with immediate toxicity of cadmium(II) ions, whereas the synthesis of stress proteins including MT starts. It is likely that the synthesis of MT is insufficient in the first day of the experiment. After the following 24 hours of the treatment the synthesis of MT increases markedly at all doses (Figure 2, column 2). In the conclusion, 
the MT level increased with increasing time of treatment at all experimental variants, which was confirmed by plotted lines (dashed line, Figure 2) with correlation coefficients $\left(\mathrm{R}^{2}\right)$ from 0.79 to 0.87 . Moreover, during the treatment the moderate differences in earthworm's weights with increasing concentration of cadmium ions were observed. At the highest cadmium dose $\left(50 \mu \mathrm{mol}^{-1}\right)$ the weight of earthworms decreased of about $10 \%$.

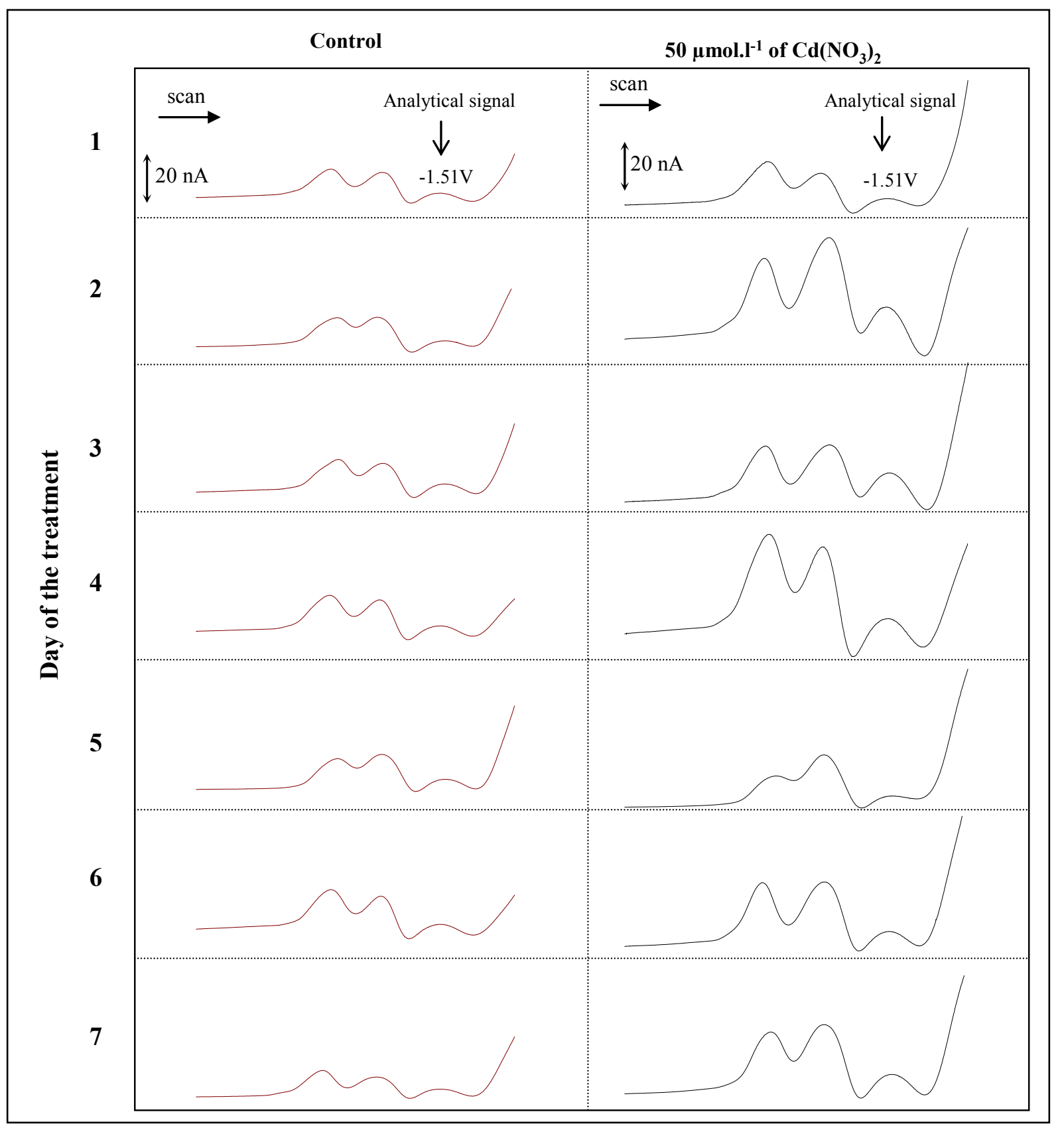

Figure 1. Differential pulse voltammograms of the control earthworms and earthworms exposed to cadmium(II) ions of $50 \mu \mathrm{mol}^{-1} \mathrm{l}^{-1}$ during the seven days long experiment. 
Table 1. The average metallothionein level in earthworms treated by cadmium ions

\begin{tabular}{|c|c|c|c|c|}
\hline \multirow{2}{*}{$\begin{array}{c}\text { Applied concentration of } \\
\mathrm{Cd}\left(\mathrm{NO}_{3}\right)_{2}\left(\mu \mathrm{mol}^{\left.-l^{-1}\right)}\right. \\
0\end{array}$} & \multirow{2}{*}{$\begin{array}{c}\text { Mean concentration of } \\
\mathbf{M T}^{\mathbf{a}, \mathbf{b}}\left(\boldsymbol{\mu ~ m o l . ~}^{\left.\mathbf{I}^{-1}\right)}\right. \\
31.6\end{array}$} & \multirow{2}{*}{$\begin{array}{c}\text { Standard deviation }^{\mathbf{a}, \mathbf{b}} \\
10.3\end{array}$} & \multicolumn{2}{|c|}{$\begin{array}{c}\text { Concentration of } \mathrm{MT}^{\mathrm{a},} \\
\text { Maximum Minimum } \\
\left(\mu \mathrm{mol.}^{\left.-\mathrm{I}^{-1}\right)}\right.\end{array}$} \\
\hline & & & 48.5 & 19.8 \\
\hline 5 & 38.0 & 15.0 & 56.1 & 17.9 \\
\hline 10 & 39.1 & 13.3 & 52.6 & 13.1 \\
\hline 20 & 45.4 & 15.5 & 68.2 & 17.8 \\
\hline 30 & 48.3 & 16.3 & 64.7 & 20.5 \\
\hline 40 & 53.3 & 25.1 & 95.6 & 21.9 \\
\hline 50 & 53.5 & 26.2 & 99.9 & 21.2 \\
\hline
\end{tabular}

${ }^{\text {a }} \ldots$ number of analyzed samples; $\mathrm{n}=5$

${ }^{\mathrm{b}}$... sample volume $(5 \mu \mathrm{l})$

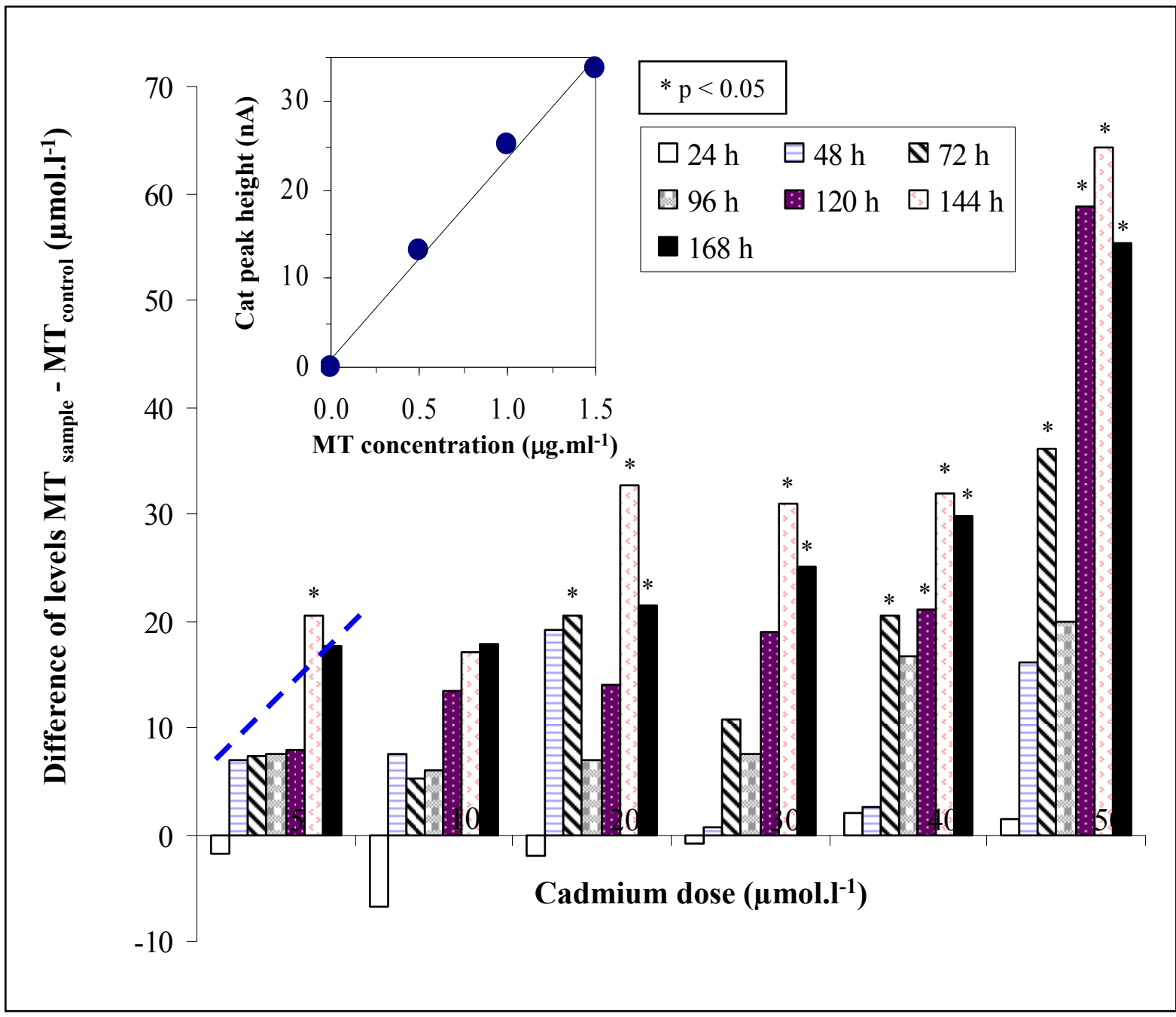

Figure 2. The differences of MT contents (MT sample $-\mathrm{MT}_{\text {control }}$ ) in earthworms kept in different cadmium concentration $\left(0,5,10,20,30,40\right.$ and $\left.50 \mu \mathrm{mol}^{-1} \mathrm{I}^{-1}\right)$ for seven days. In inset: dependence of peak height on MT concentration added to the brewery sludge. 


\subsection{Influence of the brewery sludge and/or its leach on earthworms}

Earthworms are a potentially suitable tool for biodegradation technologies of the industrial waste including sludge from waste waters. Here we were concerned with the influence of the brewery sludge on the earthworms. To compare the toxicity of the raw sludge and its leach the earthworms were used. Primarily, we determined MT concentration in the presence of brewery sludge (inset in Fig. 2). It clearly follows from the results obtained that we were able to determine MT in the presence of such complex matrix. During 14 days long experiment except the controls only earthworms kept in the leach of the sludge survived. The raw brewery sludge caused the death of the earthworms quickly. The weight of earthworms kept in the presence of leach from brewery sludge increased about $150 \%$ of their original weight because they ingested the nutrients from the sludge. The MTs content at the earthworms kept in the presence of brewery sludge leach was $11.1 \pm 0.5 \mu \mathrm{mol} . \mathrm{l}^{-1}$, whereas the content of MT in control samples was $1.2 \pm 0.4 \mu \mathrm{mol} . \mathrm{l}^{-1}$. The obtained result indicates the markedly stress of the earthworms caused by the sludge components (both organic and inorganic).

\section{Conclusion}

Biotechnologies employing invertebrates are topic. Here, we report on the investigation of the ability of earthworms (Eisenia fetida) to withstand toxic environment. We observed interesting behaviour of the earthworms treated with brewery sludge leach, at which the earthworms had higher weight compared with the control ones. This phenomenon can be connected with the overproduction of MT at the treated worms.

\section{Acknowledgements}

We gratefully acknowledge the following grant agency for financial support to this work: MSMT 6215712402 .

\section{References}

1. Ma, W.C. Estimating heavy metal accumulation in oligochaete earthworms: A meta-analysis of field data. Bull. Environ. Contam. Toxicol. 2004, 72, 663-670.

2. Booth, L.H.; Hodge, S.; O'Halloran, K. Use of biomarkers in earthworms to detect use and abuse of field applications of a model organophosphate pesticide. Bull. Environ. Contam. Toxicol. 2001, 67, 633-640.

3. Ramos, L.; Fernandez, M.A.; Gonzalez, M.J.; Hernandez, L.M. Heavy metal pollution in water, sediments, and earthworms from the Ebro River, Spain. Bull. Environ. Contam. Toxicol. 1999, 63, 305-311.

4. Fitzpatrick, L.C.; MurattiOrtiz, J.F.; Venables, B.J.; Goven, A.J. Comparative toxicity in earthworms Eisenia fetida and Lumbricus terrestris exposed to cadmium nitrate using artificial soil and filter paper protocols. Bull. Environ. Contam. Toxicol. 1996, 57, 63-68.

5. Aira, M.; Monroy, F.; Dominguez, J. Changes in microbial biomass and microbial activity of pig slurry after the transit through the gut of the earthworm Eudrilus eugeniae (Kinberg, 1867). Biol. Fertil. Soils 2006, 42, 371-376. 
6. Unwin, R.J.; Lewis, S. The Effect Upon Earthworm Populations of Very Large Applications of Pig Slurry to Grassland. Agricult. Wastes 1986, 16, 67-73.

7. Debry, J.M.; Houssiau, M.; Lemassonflorenville, M.; Wauthy, G.; Lebrun, P. Impact of Introduced Earthworm Populations on $\mathrm{Ph}$ and Nitrogen Dynamics in Soils Treated with Pig Slurry. Pedobiologia 1982, 23, 157-171.

8. Marijic, V.F.; Raspor, B. Age- and tissue-dependent metallothionein and cytosolic metal distribution in a native Mediterranean fish, Mullus barbatus, from the Eastern Adriatic Sea. Comp. Biochem. Physiol. C-Toxicol. Pharmacol. 2006, 143, 382-387.

9. Dragun, Z.; Raspor, B.; Erk, M.; Ivankovic, D.; Pavicic, J. The influence of the biometric parameters on metallothionein and metal level in the heat-treated cytosol of the whole soft tissue of transplanted mussels. Environ. Monit. Assess. 2006, 114, 49-64.

10. Kagi, J.G.R.; Schaffer, A. Biochemistry of Metallothionein. Biochemistry 1988, 27, 8509-8515.

11. Kizek, R.; Trnkova, L.; Palecek, E. Determination of metallothionein at the femtomole level by constant current stripping chronopotentiometry. Anal. Chem. 2001, 73, 4801-4807.

12. Trnkova, L.; Kizek, R.; Vacek, J. Catalytic signal of rabbit liver metallothionein on a mercury electrode: a combination of derivative chronopotentiometry with adsorptive transfer stripping. Bioelectrochemistry 2002, 56, 57-61.

13. Nordberg, M.; Nordberg, G.F. Toxicological aspects of metallothionein. Cell. Mol. Biol. 2000, 46, 451-463.

14. Strouhal, M.; Kizek, R.; Vacek, J.; Trnkova, L.; Nemec, M. Electrochemical study of heavy metals and metallothionein in yeast Yarrowia lipolytica. Bioelectrochemistry 2003, 60, 29-36.

15. Adam, V.; Petrlova, J.; Potesil, D.; Zehnalek, J.; Sures, B.; Trnkova, L.; Jelen, F.; Kizek, R. Study of metallothionein modified electrode surface behavior in the presence of heavy metal ionsbiosensor. Electroanalysis 2005, 17, 1649-1657.

16. Wu, S.M.; Jong, K.J.; Lee, Y.J. Relationships among metallothionein, cadmium accumulation, and cadmium tolerance in three species of fish. Bull. Environ. Contam. Toxicol. 2006, 76, 595-600.

17. Eroglu, K.; Atli, G.; Canli, M. Effects of metal $(\mathrm{Cd}, \mathrm{Cu}, \mathrm{Zn})$ interactions on the profiles of metallothionein-like proteins in the nile fish Oreochromis niloticus. Bull. Environ. Contam. Toxicol. 2005, 75, 390-399.

18. Martins, N.; Lopes, I.; Guilhermino, L.; Bebianno, M.J.; Ribeiro, R. Lack of evidence for metallothionein role in tolerance to copper by natural populations of Daphnia longispina. Bull. Environ. Contam. Toxicol. 2005, 74, 761-768.

19. Rovira, M.S.; Fernandez-Diaz, C.; Canavate, J.P.; Blasco, J. Effects on metallothionein levels and other stress defences in Senegal sole larvae exposed to cadmium. Bull. Environ. Contam. Toxicol. 2005, 74, 597-603.

20. Kizek, R.; Vacek, J.; Trnkova, L.; Jelen, F. Cyclic voltammetric study of the redox system of glutathione using the disulfide bond reductant tris(2-carboxyethyl)phosphine. Bioelectrochemistry 2004, 63, 19-24.

21. Petrlova, J.; Potesil, D.; Mikelova, R.; Blastik, O.; Adam, V.; Trnkova, L.; Jelen, F.; Prusa, R.; Kukacka, J.; Kizek, R. Attomole voltammetric determination of metallothionein. Electrochim. Acta 2006, 51, 5112-5119. 
22. Adam, V.; Blastik, O.; Krizkova, S.; Lubal, P.; Kukacka, J.; Prusa, R.; Kizek, R. Application of the Brdicka reaction in determination of metallothionein in patients with tumours. Chem. Listy 2008, 102, 51-58.

23. Krizkova, S.; Zitka, O.; Adam, V.; Beklova, M.; Horna, A.; Svobodova, Z.; Sures, B.; Trnkova, L.; Zeman, L.; Kizek, R. Possibilities of electrochemical techniques in metallothionein and lead detection in fish tissues. Czech J. Anim. Sci. 2007, 52, 143-148.

24. Petrlova, J.; Krizkova, S.; Zitka, O.; Hubalek, J.; Prusa, R.; Adam, V.; Wang, J.; Beklova, M.; Sures, B.; Kizek, R. Utilizing a chronopotentiometric sensor technique for metallothionein determination in fish tissues and their host parasites. Sens. Actuator B-Chem. 2007, 127, 112-119.

25. Yamamura, M.; Mori, T.; Suzuki, K.T. Metallothionein Induced in the Earthworm. Experientia 1981, 37, 1187-1189.

26. Morgan, A.J.; Sturzenbaum, S.R.; Winters, C.; Grime, G.W.; Abd Aziz, N.A.; Kille, P. Differential metallothionein expression in earthworm (Lumbricus rubellus) tissues. Ecotox. Environ. Safe. 2004, 57, 11-19.

27. Homa, J.; Olchawa, E.; Sturzenbaum, S.R.; Morgan, A.J.; Plytycz, B. Early-phase immunodetection of metallothionein and heat shock proteins in extruded earthworm coelomocytes after dermal exposure to metal ions. Environ. Pollut. 2005, 135, 275-280.

28. Sturzenbaum, S.R.; Kille, P.; Morgan, A.J. The identification, cloning and characterization of earthworm metallothionein. FEBS Lett. 1998, 431, 437-442.

29. Langdon, C.J.; Winters, C.; Sturzenbaum, S.R.; Morgan, A.J.; Charnock, J.M.; Meharg, A.A.; Piearce, T.G.; Lee, P.H.; Semple, K.T. Ligand arsenic complexation and immunoperoxidase detection of metallothionein in the earthworm Lumbricus rubellus inhabiting arsenic-rich soil. Environ. Sci. Technol. 2005, 39, 2042-2048.

30. Prusa, R.; Petrlova, J.; Kukacka, J.; Adam, V.; Sures, B.; Beklova, M.; Kizek, R. Study of interaction of glutathiones and metallothionein with cytostatics. Clin. Chem. 2006, 52, A175A175.

31. Adam, V.; Beklova, M.; Pikula, J.; Hubalek, J.; Trnkova, L.; Kizek, R. Shapes of differential pulse voltammograms and level of metallothionein at different animal species. Sensors 2007, 7, 24192429.

(C) 2008 by MDPI (http://www.mdpi.org). Reproduction is permitted for noncommercial purposes. 